Sādhanā Vol. 39, Part 2, April 2014, pp. 511-524. (C) Indian Academy of Sciences

\title{
Buckling analysis of partially corroded steel plates with irregular surfaces
}

\author{
AHMAD RAHBAR-RANJI \\ Department of Ocean Engineering, AmirKabir University of Technology, \\ Hafez Ave., Tehran, 15914, Iran \\ e-mail: rahbar@aut.ac.ir
}

MS received 19 January 2013; revised 21 August 2013; accepted 30 August 2013

\begin{abstract}
Corrosion is a long-term, inevitable process, lessens the thickness and load carrying capacity of structures. Old steel structures are more vulnerable to buckling, yielding and fracture due to corrosion. In lieu of a detailed analysis, average thickness assumption is employed for general type of corrosion. However, the estimation of load carrying capacity reduction of corroded structures typically need a much higher level of accuracy, since the actual corroded plates would have irregular surfaces. The objective of this article is to determine the effect of general corrosion on reduction of elastic buckling strength of both-sided partially corroded plates with irregular surfaces. Eigenvalue analysis using finite element method is employed for Euler stress calculation of corroded plates. The effects of different influential parameters are investigated and it is found that, aspect ratio of plate, location of corroded area, standard deviation of thickness diminution and concentration of corrosion have influence on reduction of elastic buckling strength. Reduction of elastic buckling strength is very sensitive to the amount of corrosion loss. The higher the amount of corrosion loss, the more reduction of elastic buckling strength.
\end{abstract}

Keywords. Partially corroded plate; corrosion; elastic buckling strength; FEM; irregular surface.

\section{Introduction}

The expense of maintenance, replacement and time out of service is costly. It is advantageous to develop simple methods for quick and accurate evaluation of load carrying capacity of aged structures in service. Deterioration of aged structures due to corrosion is a common problem in steel structures. For the structural safety assessment of corroded structures, load carrying capacity reduction should be determined as a function of time to plan repairs and replacements.

Different types of corrosion occurs, dry corrosion/wet corrosion, local corrosion/general corrosion. General corrosion is an attack on the metal when an electrochemical reaction proceeds over entire surface. Many research works are devoted on strength analysis of corroded plates. 
Nakai et al (2006) have performed a series of nonlinear finite element analysis (FEA) to investigate the strength of plates with pit corrosion subjected to in-plane compressive loads and bending moments. Jiang \& Guedes-Soares (2011) have studied ultimate strength of pitted plates. Huang et al (2010) have used nonlinear FEA approach for ultimate strength evaluation of corroded plates with pit corrosion. Oszvald \& Dunai (2010) have studied experimentally and numerically elastic buckling of corroded steel angle elements.

Significant relevant works have been done in the area of strength evaluation of corroded structures. However, none of them have involved the sort of simulated corroded surfaces applied in the current work. Actual thickness distribution of corroded plates is time dependent variable and should be expressed as a function of corrosion degree. Strength analysis of such plates could yield some acceptance criteria to assist surveyors or designers in repair and replacement planning.

Limited number of research works are investigated time dependent surface geometries of plates due to corrosion. Rahbar-Ranji (2001) has proposed a spectrum for random simulation of geometry of corroded surface based on the mean and standard deviation of thickness diminution. Rahbar-Ranji (2012a, b, 2013a, b) has used this spectrum to analyse plastic collapse load, ultimate strength, shear buckling strength and elastic buckling strength of corroded plates with irregular surfaces. He has concluded that though maximum reduction of plastic collapse load occurs in one-sided corroded plates, however buckling strength of one- and both-sided corroded plates are the same.

It is the main aim of present work to determine elastic buckling strength of corroded steel plates with both-sided corroded surfaces. Undulated surfaces are generated based on power spectrum (Rahbar-Ranji 2001) and Euler stresses are calculated using finite element method (FEM). A non-dimensional buckling strength ratio is introduced to investigate the effect of influential parameters.

\section{Geometry of corroded surface}

Steel plate that has been exposed to corrosive environments exhibits characteristically irregular surfaces and one would expect that the thickness of plate varies from point-to-point as follows:

$$
t\left(x_{1}, x_{2}\right)=t_{\mathrm{avr}}+\zeta^{+}\left(x_{1}, x_{2}\right)+\zeta^{-}\left(x_{1}, x_{2}\right),
$$

where $\zeta^{+}\left(x_{1}, x_{2}\right)$ and $\zeta^{-}\left(x_{1}, x_{2}\right)$ are distance of points on top and bottom of undulated surfaces from average thickness plane on either sides, respectively (figure 1). Simulation techniques are used to generate artificial data, since it is not feasible to measure all points. One of these techniques is Monte Carlo simulation methodology which generates a sample function of the stochastic process. Among the various methods that have been developed to generate such sample functions, the spectral representation method (Goda 1970) is one of the most widely used today.

Power spectrum, $S(k)$, is another way of representing a series of sampling data, $\zeta(x)$, based on wave number, $k$, which shows the contribution of different wave numbers in the series. If $\zeta(x)$ exhibits some approximate repetition on $k$, the spectrum at the vicinity of $k$ would have a local peak.

Two-dimensional spectrums of geometry of corroded surfaces on top/bottom and in longitudinal/transverse directions of a heavily corroded plate were calculated using Fast Fourier 


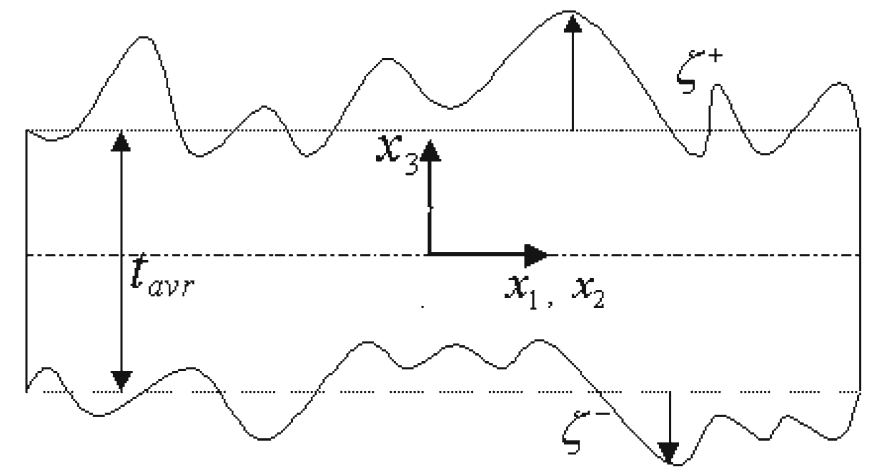

Figure 1. Geometry of a plate with undulated surfaces.

Transform (FFT) method. Based on these calculations, an equation for spectrum of corroded surface is proposed as follows (Rahbar-Ranji 2001):

$$
S(k)=\left\{\begin{array}{cc}
\frac{11.88 \alpha \beta \sigma}{k^{2}} \operatorname{Exp}\left(-\frac{2}{3}\left(\frac{\beta}{2.97 \sigma|k|}\right)^{3}\right) & \Delta t_{\mathrm{avr}} \leq 2.97 \sigma \\
\frac{\alpha \beta\left(\Delta t_{\mathrm{avr}}+2.97 \sigma\right)^{2}}{\Delta t_{\mathrm{avr}} k^{2}} \operatorname{Exp}\left(-\frac{2}{3}\left(\frac{\beta}{\Delta t_{\mathrm{avr}}|k|}\right)^{3}\right) & \Delta t_{\mathrm{avr}} \geq 2.97 \sigma,
\end{array}\right.
$$

where $k$ is wave number, $\Delta t_{\mathrm{avr}}$ and $\sigma$ are the average and standard deviation of thickness diminution, respectively, and $\alpha$ and $\beta$ are two fitting constants which are dependent on corrosion condition and lie in the following ranges:

$$
\begin{aligned}
& \alpha=0.01 \sim 0.15 \\
& \beta=0.02 \sim 0.15 .
\end{aligned}
$$

Figure 2 shows some of the calculated spectrums which are compared with the proposed spectrum. Statistical features of surface irregularities can be characterized by equation (2) and parameters $\alpha$ and $\beta$. These two parameters are defined in such a way that statistical characteristics of simulated surface be the same as target surface. Equation (2) is derived based on type I asymptotic distribution rule for calculation of extreme values of thickness diminution. Maximum thickness diminution is assumed as extreme largest corrosion depth with cumulative probability of $95 \%$ and minimum thickness diminution is assumed as smallest corrosion depth with cumulative probability of $5 \%$. According to type I asymptotic distribution rule, these parameters are defined as follows

$$
\left\{\begin{array}{l}
\Delta t_{\max }=\Delta t_{\mathrm{avr}}+2.97 \sigma \\
\Delta t_{\min }=\Delta t_{\mathrm{avr}}-2.97 \sigma .
\end{array}\right.
$$

Maximum thickness diminution is assumed as the extreme largest corrosion depth and minimum thickness diminution is assumed as the smallest corrosion depth (figure 3).

Stochastic characteristics in all directions should be the same, since corrosion is a random phenomenon. Therefore, an isotropic three-dimensional spectrum is expressed by equation (2) where equivalent wave number $k$ is defined as follows:

$$
k_{\mathrm{eq}}=\sqrt{k_{1}^{2}+k_{2}^{2}} .
$$



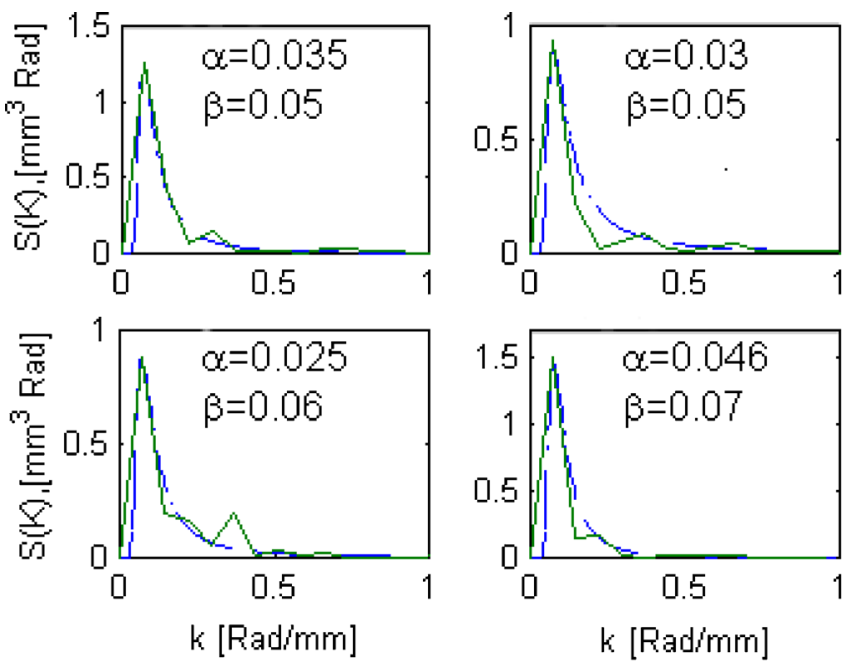

Calculated - - - - Proposed

Figure 2. Calculated and proposed spectrum of corroded surface.

Having spectrum of corroded surface, geometry of corroded surface is generated as follows (Goda 1970):

$$
\begin{aligned}
\zeta\left(x_{1}, x_{2}\right)= & \sqrt{2} \sum_{i=1}^{N_{1}} \sum_{j=1}^{N_{2}} \sqrt{2 S\left(k_{1 i}, k_{2 j}\right) \Delta k_{1} \Delta k_{2}} \\
& \times\left(\operatorname{Cos}\left(k_{1 i} x_{1}+k_{2 j} x_{2}+\phi_{1 i j}\right)+\operatorname{Cos}\left(k_{1 i} x_{1}-k_{2 j} x_{2}+\phi_{2 i j}\right)\right),
\end{aligned}
$$

where $\zeta\left(x_{1}, x_{2}\right)$ are the ordinates of points from a reference plane, $N_{1}$ and $N_{2}$ are the number of discretization of the spectrum in $x_{1}$ and $x_{2}$ directions, respectively, $\phi_{1 i j}$ and $\phi_{2 i j}$ are random phase angles uniformly distributed between 0 and $2 \pi, \Delta k_{1}$ and $\Delta k_{2}$ are wave number increments in $x_{1}$ and $x_{2}$ directions, respectively, and $k_{1 i}=i \Delta k_{1}$ and $k_{2 j}=j \Delta k_{2}$.

Depending upon conditions, corrosion may occur at one or both sides of plates. In this work, elastic buckling strength of both-sided corroded plates have been investigated, since elastic buckling strength of one- and both-sided corroded plates are the same (Rahbar-Ranji 2013b).

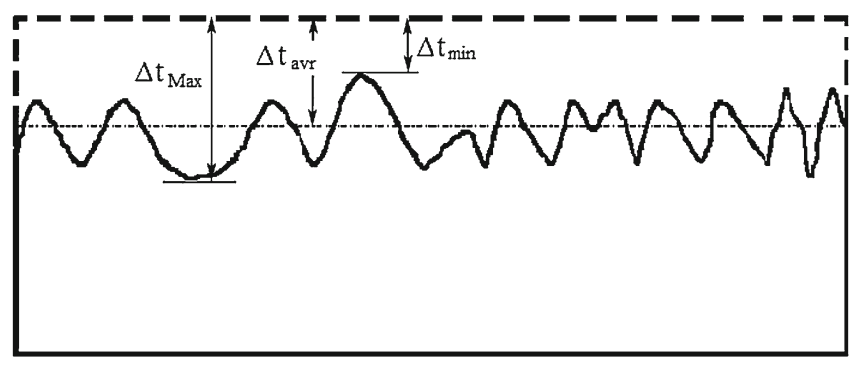

Figure 3. Definition of $\Delta t_{\max }, \Delta t_{\mathrm{avr}}$ and $\Delta t_{\min }$ for corroded surface. 
Irregular thickness of both-sided corroded plates with the same irregular surfaces at each side is determined as follows

$$
t\left(x_{1}, x_{2}\right)=t_{0}-\Delta t_{\mathrm{avr}}+\zeta\left(x_{1}, x_{2}\right),
$$

where $t_{0}$ is initial thickness of the plate.

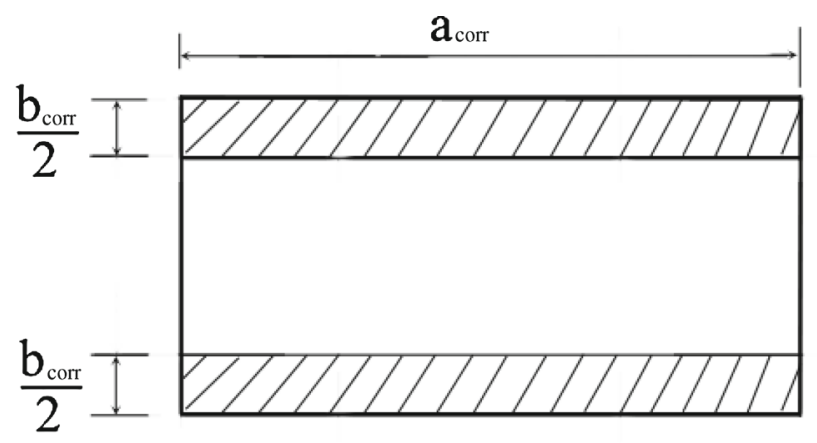

a) Corrosion pattern No.1, Corroded patch at longitudinal edges of plate

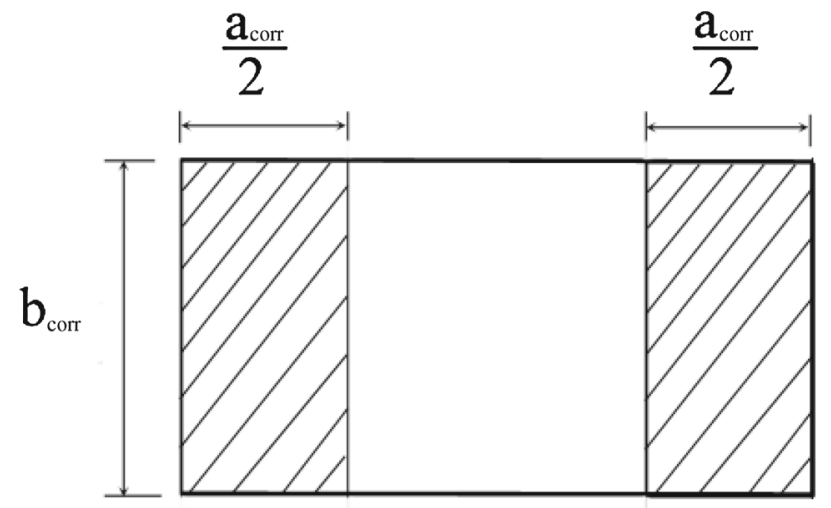

b) Corrosion pattern No.2, Corroded area at transverse edges of plate

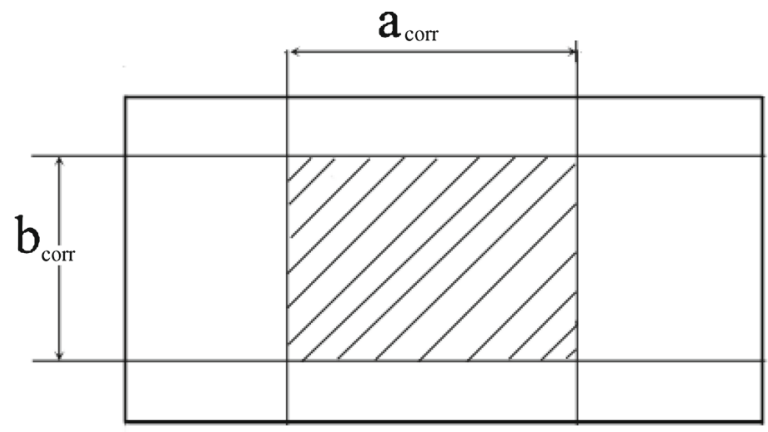

c) Corrosion pattern No.3, Corroded patch at centre of plate

Figure 4. Corrosion patterns considered in this work. 


\subsection{Corrosion conditions}

Corrosion in steel structures shows a wide variation which depends on environment, age of structure, type of material, function, protecting system, and frequency of cleaning/repairing. One would expect to express the spectrum of corroded surface as a function of above mentioned variables, which are called external-environmental-variables. It is not feasible to measure ordinates of corroded plates in all possible environment-structure systems in order to determine spectrum of corroded surface as a function of external-environmentalvariables. Thus, spectrum of corroded surface is expressed as a function of geometry parameters (average and standard deviation of thickness diminution), which are called internal parameters.

Prediction of average and standard deviation of thickness diminution in any environmentstructure systems were the subject of many studies in the recent years. These studies are mostly done by data measurements on existing corroded structures and in some instances are supported by experiments. Based on these studies, some approximate linear, bilinear and nonlinear equations are proposed to estimate the average and standard deviation of thickness diminution of corroded structures. Guo et al (2008) have summarized the existing corrosion wastage models and have calculated the mean and standard deviation of corrosion wastage. They have concluded that corrosion wastage measurements spread over a wide range, mean and standard deviation fluctuate with time and maximum corrosion loss is much higher than average value.

In this study mean thickness diminution is assumed as $0.5 \mathrm{~mm}$ and standard deviation of thickness diminution is assumed as $0.1 \mathrm{~mm}$. Three different corrosion patterns (figure 4) are considered and for each case a random irregular surface is generated. In this figure, $a_{\text {corr }}$ is the length of corroded area and $b_{\text {corr }}$ is the width of corroded area. Table 1 shows statistical characteristics of generated surfaces for corrosion pattern No. 1 with ratio of corroded area over plate area equal to $0.5\left(a_{\text {corr }}=1 / 2 a, b_{\text {corr }}=1 / 2 b\right)$. As can be seen, parameters $\alpha$ and $\beta$ are chosen in such a way that $\Delta t_{\mathrm{avr}}$ and $\sigma$ of the simulated surface be the same as target values.

Table 1. Statistical characteristics of simulated surface, corrosion conditions $\Delta t_{\mathrm{avr}}=0.5 \mathrm{~mm}, \sigma=0.1 \mathrm{~mm}$ (corrosion pattern No. 1, ratio of corroded area over plate area 0.50 ).

\begin{tabular}{lcccc}
\hline $\begin{array}{l}\text { Size of plate } \\
(\mathrm{mm})\end{array}$ & \multicolumn{4}{c}{ Simulated surface } \\
\cline { 2 - 5 } $600 \times 600$ & $0.203^{\mathrm{a}}$ & $0.506^{\mathrm{a}}$ & $0.830^{\mathrm{a}}$ & $0.100^{\mathrm{a}}$ \\
& 0.203 & 0.506 & 0.850 & 0.099 \\
$600 \times 1200$ & 0.203 & 0.498 & 0.819 & 0.098 \\
& 0.203 & 0.509 & 0.886 & 0.095 \\
$600 \times 1800$ & 0.203 & 0.509 & 0.848 & 0.101 \\
& 0.203 & 0.505 & 0.886 & 0.096 \\
$600 \times 2400$ & 0.203 & 0.501 & 0.870 & 0.100 \\
& 0.203 & 0.502 & 0.872 & 0.096 \\
$600 \times 3000$ & 0.203 & 0.506 & 0.917 & 0.098 \\
& 0.203 & 0.498 & 0.865 & 0.098 \\
\hline
\end{tabular}

${ }^{\text {a }}$ Simulated surface characteristics at each corrosion patches. 


\section{Elastic buckling analysis of plates}

Euler stress for buckling of a rectangular plate panel with four edges simply supported is as follows (Timoshenko \& Gere 1961)

$$
\sigma_{P E}=\left(m \frac{b}{a}+\frac{1}{m} \frac{a}{b}\right)^{2} \frac{\pi^{2} D_{P}}{b^{2} t_{P}}
$$

where $D_{P}$ is plate bending rigidity and is defined as follows

$$
D_{P}=\frac{E t_{P}^{3}}{12\left(1-v^{2}\right)},
$$

where $t_{P}$ is the thickness of plate, $a$ is the length of plate, $b$ is the width of plate, $E$ is Young's modulus, $v$ is Poisson's ratio and $m$ is the number of half waves in longitudinal direction and should be determined in such a way that $\sigma_{P E}$ be minimum.

\section{Numerical analysis and discussions}

Elastic buckling assessment of corroded plates with irregular surfaces is only on the basis of numerical analysis with FEM. Using shell elements with variable thickness at each node, bothsided corroded plate with the same irregular surfaces at each sided is generated. In this case mid-plane of corroded plate is not dislocated. A computer code in Fortran 90 is developed to generate irregular surfaces based on mean and standard deviation of thickness diminution. Substituting ordinates of this surface, $\zeta\left(x_{1}, x_{2}\right)$, in equation (6), irregular thickness of each nodes are determined.

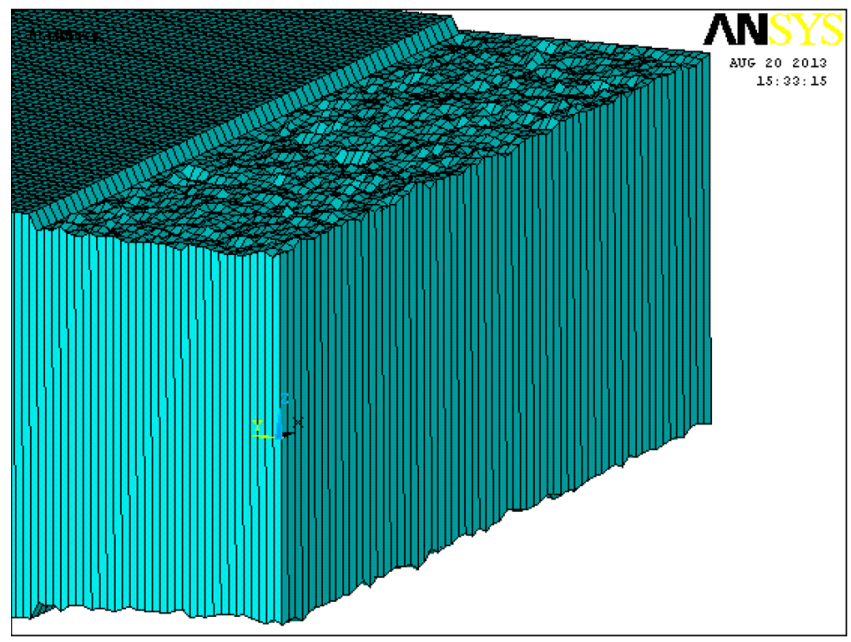

Figure 5. Finite element model of a partially both-sided corroded plate (shell elements). 
Eigenvalue analyses are performed using computer code ANSYS (version 5.6). Both-sided corroded plates are modelled using four-node quadrilateral shell element, SHELL63. This fournode quadrilateral shell element is capable of modelling elastic behaviour and can simulate both membrane and flexural behaviours. In addition, it has three rotational and three translational degrees of freedom per node. Figure 5 shows FE model of a partially corroded plate with irregular surfaces.

A uniformly distributed normal stress is applied over one end while holding the other end. Rectangular steel plates with $E=206 \mathrm{GPa}, v=0.3$, thickness 6-14 mm, width $600 \mathrm{~mm}$, and length 600-3000 $\mathrm{mm}$ are considered.
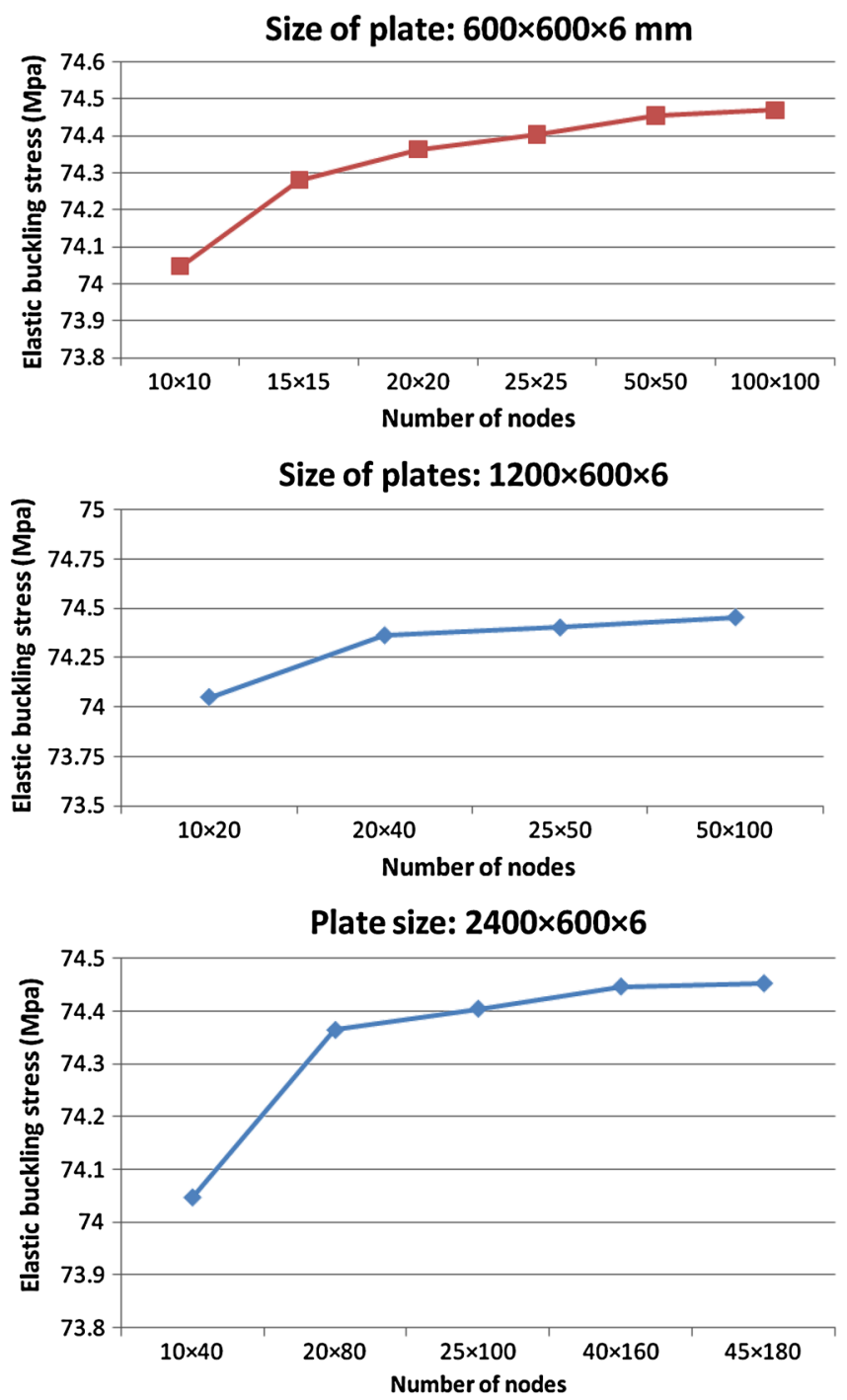

Figure 6. Convergence curve for elastic buckling stress of rectangular plates, constant thickness under uniform loading. 


\subsection{Convergence studies and verification of FE model accuracy}

To check the accuracy of the FE models and determine appropriate mesh size, some preliminary un-corroded plates are analysed. Figure 6 shows accuracy and convergence study of FEM using different densities of nodes. Rectangular plates with constant thickness subjected to uniform distributed loading is considered. As can be seen the results converge very fast and for plate with dimension $600 \times 600 \mathrm{~mm}$, with $25 \times 25$ number of nodes accurate result is achieved. For plates with larger dimensions, the same ratio of number of meshes over plate size, yields accurate results. Therefore, in further analyses this ratio of number of meshes over plate size is adopted.

Euler stress for plates with irregular surfaces are calculated by using FEM and compared with Euler stress of un-corroded plates. For each case a buckling strength ratio is defined as follows

$$
R=\frac{\left(\sigma_{P E}\right)_{\text {Corr }}}{\left(\sigma_{P E}\right)_{\text {Un-corr }}} .
$$

Table 2 shows Euler stress and buckling strength ratio for corrosion pattern No. 1, with different aspect ratio and thickness of plate. As can be seen, aspect ratio of plate has no significant effect

Table 2. Euler stress for plate buckling, corrosion conditions $\Delta t_{\mathrm{avr}}=0.5 \mathrm{~mm}, \sigma=0.1 \mathrm{~mm}$ (corrosion pattern No.1, ratio of corroded area over plate area $0.50, a_{\text {corr }}=1 / 2 a, b_{\text {corr }}=1 / 2 b$ ).

\begin{tabular}{|c|c|c|c|c|}
\hline \multirow{2}{*}{$\begin{array}{l}\text { Size of plate, } \\
\mathrm{mm}\end{array}$} & \multirow{2}{*}{$\begin{array}{l}\text { Corrosion } \\
\text { loss }\end{array}$} & \multicolumn{3}{|c|}{ Euler stress (MPa) } \\
\hline & & $\left(\sigma_{P E}\right)_{\text {Corr }}$ & $\left(\sigma_{P E}\right)_{\text {Un-corr }}$ & $R$, Buckling strength ratio \\
\hline $600 \times 600 \times 6$ & $4.7 \%$ & 67.48 & 74.47 & $90.6 \%$ \\
\hline $1200 \times 600 \times 6$ & $4.4 \%$ & 67.85 & 74.47 & $91.1 \%$ \\
\hline $1800 \times 600 \times 6$ & $4.5 \%$ & 67.70 & 74.47 & $90.9 \%$ \\
\hline $2400 \times 600 \times 6$ & $4.5 \%$ & 67.63 & 74.47 & $90.8 \%$ \\
\hline $3000 \times 600 \times 6$ & $4.5 \%$ & 67.65 & 74.47 & $90.8 \%$ \\
\hline $600 \times 600 \times 8$ & $3.5 \%$ & 123.04 & 132.40 & $92.9 \%$ \\
\hline $1200 \times 600 \times 8$ & $3.3 \%$ & 123.53 & 132.40 & $93.3 \%$ \\
\hline $1800 \times 600 \times 8$ & $3.4 \%$ & 123.34 & 132.40 & $93.2 \%$ \\
\hline $2400 \times 600 \times 8$ & $3.4 \%$ & 123.21 & 132.40 & $93.1 \%$ \\
\hline $3000 \times 600 \times 8$ & $3.4 \%$ & 123.24 & 132.40 & $93.1 \%$ \\
\hline $600 \times 600 \times 10$ & $2.8 \%$ & 195.14 & 206.87 & $94.3 \%$ \\
\hline $1200 \times 600 \times 10$ & $2.7 \%$ & 195.76 & 206.87 & $94.6 \%$ \\
\hline $1800 \times 600 \times 10$ & $2.7 \%$ & 195.51 & 206.87 & $94.5 \%$ \\
\hline $2400 \times 600 \times 10$ & $2.7 \%$ & 195.34 & 206.87 & $94.4 \%$ \\
\hline $3000 \times 600 \times 10$ & $2.7 \%$ & 195.35 & 206.87 & $94.4 \%$ \\
\hline $600 \times 600 \times 12$ & $2.4 \%$ & 283.79 & 297.90 & $95.3 \%$ \\
\hline $1200 \times 600 \times 12$ & $2.2 \%$ & 284.54 & 297.90 & $95.5 \%$ \\
\hline $1800 \times 600 \times 12$ & $2.3 \%$ & 284.22 & 297.90 & $95.4 \%$ \\
\hline $2400 \times 600 \times 12$ & $2.3 \%$ & 284.00 & 297.90 & $95.3 \%$ \\
\hline $3000 \times 600 \times 12$ & $2.3 \%$ & 284.01 & 297.90 & $95.3 \%$ \\
\hline $600 \times 600 \times 14$ & $2.0 \%$ & 388.98 & 405.47 & $95.9 \%$ \\
\hline $1200 \times 600 \times 14$ & $1.9 \%$ & 389.86 & 405.47 & $96.1 \%$ \\
\hline $1800 \times 600 \times 14$ & $1.9 \%$ & 389.48 & 405.47 & $96.1 \%$ \\
\hline $2400 \times 600 \times 14$ & $1.90 \%$ & 389.20 & 405.70 & $96.0 \%$ \\
\hline $3000 \times 600 \times 14$ & $1.9 \%$ & 389.19 & 405.47 & $96.0 \%$ \\
\hline
\end{tabular}


Table 3. Euler stress for plate buckling corrosion conditions $\Delta t_{\mathrm{avr}}=0.5 \mathrm{~mm}, \sigma=0.1 \mathrm{~mm}$ (corrosion pattern No. 2, ratio of corroded area over plate area $\left.0.50, a_{\text {corr }}=1 / 2 a, b_{\text {corr }}=1 / 2 b\right)$.

\begin{tabular}{|c|c|c|c|c|}
\hline \multirow{2}{*}{$\begin{array}{l}\text { Size of plate, } \\
\mathrm{mm}\end{array}$} & \multirow{2}{*}{$\begin{array}{l}\text { Corrosion } \\
\text { loss }\end{array}$} & \multicolumn{3}{|c|}{ Euler stress (MPa) } \\
\hline & & $\left(\sigma_{P E}\right)_{\mathrm{Corr}}$ & $\left(\sigma_{P E}\right)_{\text {Un-corr }}$ & $R$, Buckling strength ratio \\
\hline $600 \times 600 \times 6$ & $4.6 \%$ & 69.61 & 74.47 & $93.5 \%$ \\
\hline $1200 \times 600 \times 6$ & $4.6 \%$ & 66.27 & 74.47 & $89.0 \%$ \\
\hline $1800 \times 600 \times 6$ & $4.7 \%$ & 65.44 & 74.47 & $87.9 \%$ \\
\hline $2400 \times 600 \times 6$ & $4.7 \%$ & 63.75 & 74.47 & $85.6 \%$ \\
\hline $3000 \times 600 \times 6$ & $4.5 \%$ & 63.23 & 74.47 & $84.9 \%$ \\
\hline $600 \times 600 \times 8$ & $3.5 \%$ & 126.06 & 132.40 & $95.2 \%$ \\
\hline $600 \times 600 \times 10$ & $2.8 \%$ & 199.04 & 206.87 & $96.2 \%$ \\
\hline $600 \times 600 \times 12$ & $2.3 \%$ & 288.57 & 297.90 & $96.9 \%$ \\
\hline $600 \times 600 \times 14$ & $2.0 \%$ & 394.65 & 405.47 & $97.3 \%$ \\
\hline
\end{tabular}

on reduction of buckling strength of corroded plate. However, for the same size of plate, by decreasing thickness of plate, reduction of buckling strength increases. To express the effect of plate thickness on reduction of buckling strength, a parameter called corrosion loss is introduced as follows

$$
\text { Corrosion loss }=\frac{\text { Lost weight }}{\text { Initial weight }} .
$$

The values of corrosion loss are presented in table 2 . It can be concluded that by increasing the amount of corrosion lost, reduction of buckling strength increases and corroded plate is more prone to buckling. Tables 3 and 4 show Euler stress and buckling strength ratio for corrosion patterns No. 2 and No. 3, respectively when ratio of corroded area over plate area is $0.5\left(a_{\text {corr }}=\right.$ $\left.1 / 2 a, b_{\text {corr }}=1 / 2 b\right)$. As can be seen, in contrast to corrosion pattern No. 1 , when corrosion concentrates at the centre or transverse edges of plate, aspect ratio of plate has influence on buckling strength ratio.

Figures 7-9 show buckling strength ratio as a function of corrosion loss for different corroded area and corrosion patterns. As can be seen, buckling strength ratio decreases by increasing corrosion loss, regardless of corrosion pattern and ratio of corroded area.

Table 4. Euler stress for plate buckling corrosion conditions $\Delta t_{\mathrm{avr}}=0.5 \mathrm{~mm}, \sigma=0.1 \mathrm{~mm}$ (corrosion pattern No. 3, ratio of corroded area over plate area $0.50, a_{\text {corr }}=1 / 2 a, b_{\text {corr }}=1 / 2 b$ ).

\begin{tabular}{|c|c|c|c|c|}
\hline \multirow{2}{*}{$\begin{array}{l}\text { Size of plate, } \\
\mathrm{mm}\end{array}$} & \multirow{2}{*}{$\begin{array}{l}\text { Corrosion } \\
\text { loss }\end{array}$} & \multicolumn{3}{|c|}{ Euler stress $(\mathrm{MPa})$} \\
\hline & & $\left(\sigma_{P E}\right)_{\text {Corr }}$ & $\left(\sigma_{P E}\right)_{\mathrm{Un} \text {-corr }}$ & $R$, Buckling strength ratio \\
\hline $600 \times 600 \times 6$ & $2.5 \%$ & 67.63 & 74.47 & $90.8 \%$ \\
\hline $1200 \times 600 \times 6$ & $2.5 \%$ & 70.05 & 74.47 & $94.1 \%$ \\
\hline $1800 \times 600 \times 6$ & $2.5 \%$ & 72.67 & 74.47 & $97.6 \%$ \\
\hline $2400 \times 600 \times 6$ & $2.4 \%$ & 69.72 & 74.47 & $93.6 \%$ \\
\hline $3000 \times 600 \times 6$ & $2.4 \%$ & 68.83 & 74.47 & $92.4 \%$ \\
\hline $600 \times 600 \times 8$ & $1.9 \%$ & 123.24 & 132.40 & $93.1 \%$ \\
\hline $600 \times 600 \times 10$ & $1.5 \%$ & 195.40 & 206.87 & $94.4 \%$ \\
\hline $600 \times 600 \times 12$ & $1.3 \%$ & 284.12 & 297.90 & $95.4 \%$ \\
\hline $600 \times 600 \times 14$ & $1.1 \%$ & 389.39 & 405.47 & $96.0 \%$ \\
\hline
\end{tabular}



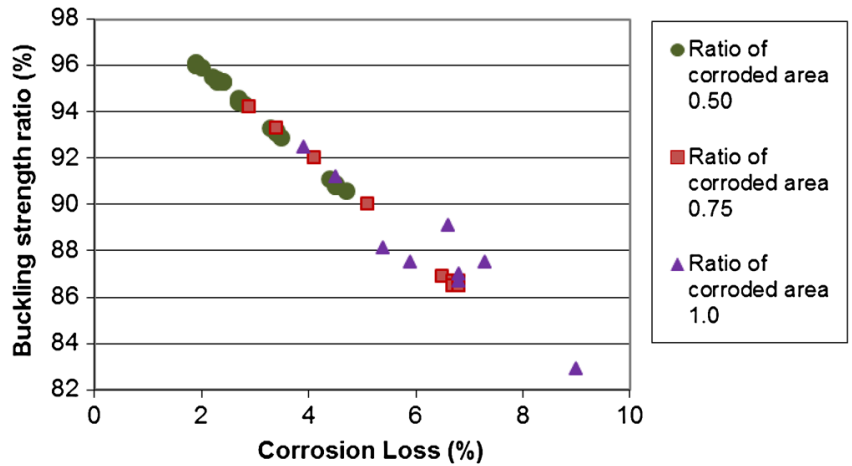

Figure 7. Buckling strength ratio of corroded plate, corrosion conditions $\Delta t_{\mathrm{avr}}=0.5 \mathrm{~mm}, \sigma=0.1 \mathrm{~mm}$, corrosion pattern No. 1.
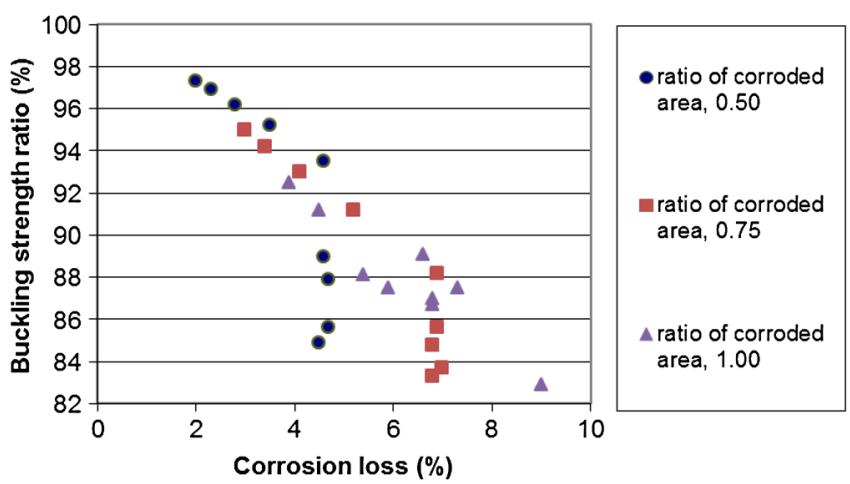

Figure 8. Buckling strength ratio of corroded plate, corrosion conditions $\Delta t_{\mathrm{avr}}=0.5 \mathrm{~mm}, \sigma=0.1 \mathrm{~mm}$, corrosion pattern No. 2.

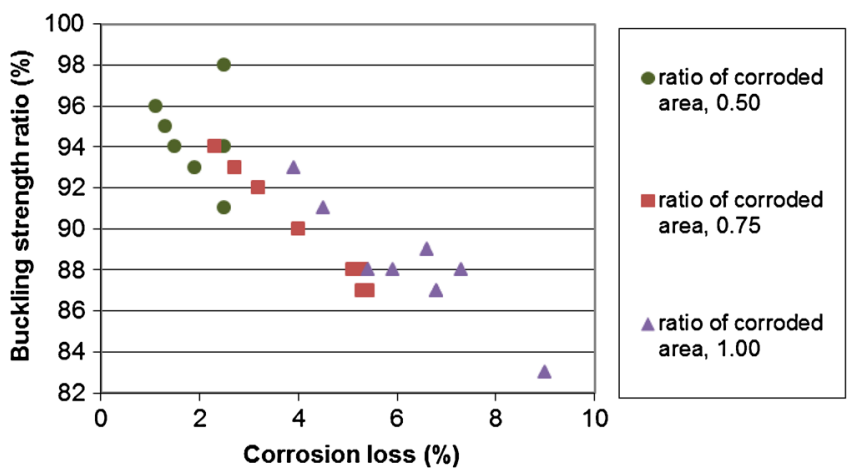

Figure 9. Buckling strength ratio of corroded plate, corrosion conditions $\Delta t_{\mathrm{avr}}=0.5 \mathrm{~mm}, \sigma=0.1 \mathrm{~mm}$, corrosion pattern No. 3 . 


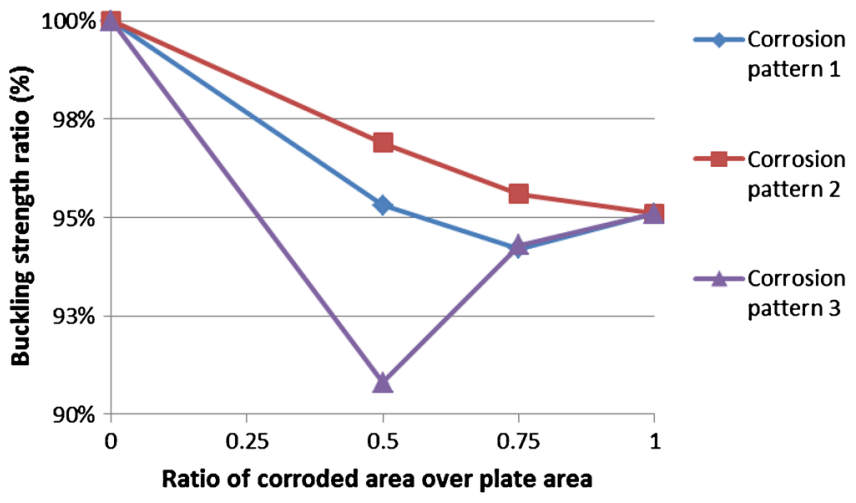

Figure 10. Buckling strength ratio as a function of corroded area for different corrosion patterns, corrosion loss $2.5 \%$.

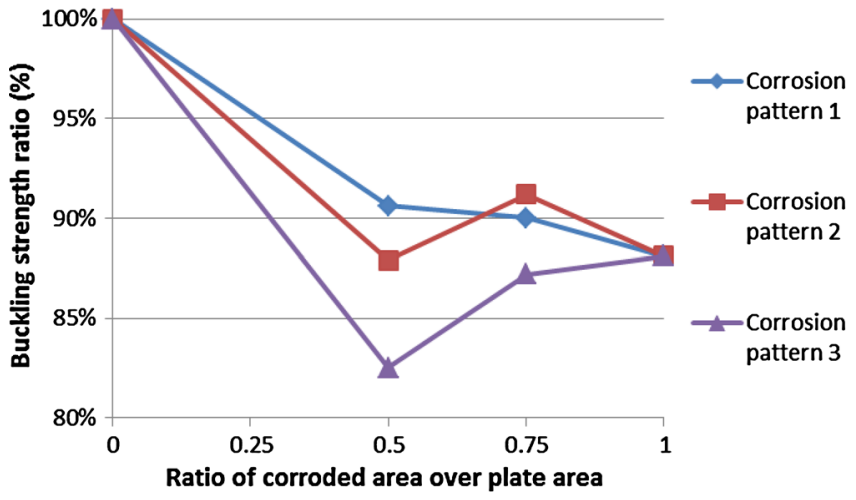

Figure 11. Buckling strength ratio as a function of corroded area for different corrosion patterns, corrosion loss $5.0 \%$.

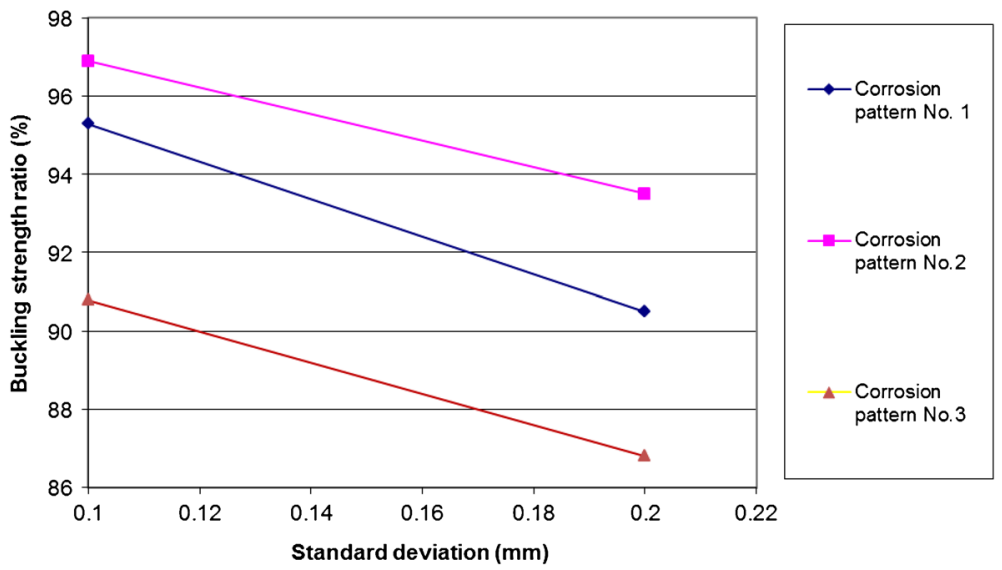

Figure 12. Buckling strength ratio as a function of standard deviation of thickness diminution, ratio of corroded area, 0.5. 
Figures 10 and 11 show buckling strength ratio as a function of ratio of corroded area for two different amount of corrosion loss. As can be seen, by increasing ratio of corroded area, strength ratio decreases. Also, it can be concluded that for the same amount of corroded area, corrosion pattern No. 3 yields the lowest buckling strength. Therefore, when corrosion is concentrated at the centre of plate, reduction of buckling strength is more than when it is concentrated at the edges.

Figure 12 shows buckling strength ratio as a function of standard deviation. In this figure corrosion loss is about $5 \%$ and ratio of corroded area is 0.5 . As can be seen by increasing standard deviation of thickness diminution, buckling strength ratio decreases. In another words, by increasing roughness of surface and keeping corrosion loss constant, buckling strength reduces.

\section{Conclusions}

There is little study on load carrying capacity of corroded plates with rough surfaces especially as a function of corrosion conditions. Eigenvalue analysis by using FEM is used for calculation of elastic buckling stress of corroded plates with both-sided irregular surfaces. A buckling strength ratio is introduced as a ratio of elastic buckling stress of corroded plate with irregular thickness at each node with respect to elastic buckling stress of un-corroded plate. Influential parameters are studied and it was found that standard deviation has weakening effect on buckling strength ratio. Influence of aspect ratio on buckling strength depends on corrosion pattern. Location of corroded area has influence on reduction of buckling strength. When corrosion occurs at the centre of plate, reduction of buckling strength is higher than when it occurs at the edges. By increasing the ratio of corroded area, reduction of buckling strength would be higher. The most influential parameter on buckling strength of corroded plate is the amount of corrosion loss. The higher the amount of corrosion loss, the more reduction of elastic buckling strength.

\section{References}

Goda Y 1970 Numerical experiments on wave statistics with spectral simulation. Rep. Port Harbor Res. Inst. 9(3): 3-57

Guo J, Wang G, Ivanov L and Perakis N 2008 Time varying ultimate strength of aging tanker deck plate considering corrosion effect. Mar. Struct. 21: 402-419

Huang Y, Zhang Y, Liu G and Zhang Q 2010 Ultimate strength assessment of hull structural plate with pitting corrosion damnification under biaxial compression. Ocean Eng. 37: 1503-1512

Jiang X and Guedes-Soares C 2011 Ultimate capacity behaviour of pitted steel plates under biaxial compression. Proc. $30^{\text {th }}$ Internat. Conf. Ocean, Offshore and Arctic Eng. (OMAE 2011); Rotterdam, The Netherland. New York, USA: ASME; OMAE2011-49980

Nakai T, Matsushita H and Yamamoto N 2006 Effect of pitting corrosion on the ultimate strength of steel plates subjected to in-plane compression and bending. J. Mar. Sci. Tech. 11(1): 52-64

Oszvald K and Dunai L 2010 Effect of corrosion on the buckling of steel angle elements. 8th fib PhD Symp. in Kgs. Lyngby, Denmark

Rahbar-Ranji A 2001 Stress analysis of a randomly undulated plate due to corrosion in marine structures. Ph.D. Thesis, Yokohama National University, Department of Naval Architecture, Japan

Rahbar-Ranji A 2012a Plastic collapse load of corroded steel plates. Sadhana-Academy Proc. Eng. Sci. 37(3): 341-349

Rahbar-Ranji A 2012b Ultimate strength of corroded steel plates with irregular surfaces under in-plane compression. Ocean Eng. 54: 261-269 
Rahbar-Ranji A 2013a Shear buckling strength of corroded steel plates with irregular surfaces. J. Zhejiang University-SCIENCE A (Applied Physics \& Eng), doi:10.1631/jzus.A1200163 (in press)

Rahbar-Ranji A 2013b Elastic buckling strength of corroded steel plates. Sadhana-Academy Proc. Eng. Sci. 38(1): 89-99

Timoshenko S P and Gere J M 1961 Theory of elastic stability. 2nd ed, Engineering Societies Monograph, NY: McGraw Hill 